\title{
INSTITUIÇÓES JURÍDICAS, ESTADO DE DIREITO E CRESCIMENTO ECONÔMICO
}

\author{
LEGAL INSTITUTIONS, RULE OF LAW AND ECONOMIC GROWTH
}

\author{
Aline Gadelha de Paula \\ Doutora em Economia pela Universidade Católica de Brasilia, UCB/DF. \\ Economista na Defensoria Pública da União \\ aline.paula@dpu.def.br
}

\section{RESUMO}

Este artigo investiga as relaçóes existentes entre qualidade das instituiçôes jurídicas e crescimento econômico dos países. Considerando a importância de se incorporar a análise institucional no estudo do desempenho econômico dos países, o objetivo principal desta pesquisa consiste em investigar como o nível de qualidade das instituiçóes jurídicas vigentes nos países afeta os seus resultados econômicos. Para tanto, utilizou-se uma metodologia empírica e uma amostra de dados de 118 países, para um período de 15 anos, compreendido entre os anos de 2002 a 2016. Desenvolveu-se um modelo econométrico capaz de captar os efeitos de uma melhoria - choque positivo - na qualidade das instituiçóes jurídicas sobre a trajetória futura do desempenho econômico dos países. Ademais, observou-se como esses efeitos variam de acordo com o nível de renda dos países. Os resultados sugerem que melhorias na qualidade das instituiçôes jurídicas afetam positivamente o desempenho econômico, contribuindo para uma trajetória de crescimento e prosperidade econômica dos países. Esses efeitos positivos do nível de qualidade institucional jurídica tendem a ser mais relevantes e significativos em países de baixa renda que apresentam instituiçóes relativamente mais fracas.

Palavras-chave: Instituições Jurídicas. Crescimento Econômico. Estado de Direito. VAR em Painel.

\begin{abstract}
This paper investigates the relationship between quality of legal institutions and economic growth of countries. Considering the importance of incorporating institutional analysis in the study of countries' economic performance, the main objective of this research is to investigate how the quality level of current legal institutions in countries affects their economic results. Therefore, it requires an empirical methodology and a sample of 118 countries in a period of 15 years, from 2002 to 2016. This work developed an econometric model capable of capturing the effects of an improvement — positive shock - on the quality of legal institutions over the future trajectory of countries' economic performance. Moreover, it was observed how these effects vary according to the income level of those countries. The results suggest that improvements in the quality of legal
\end{abstract}


institutions positively affect economic performance, contributing to a trajectory of economic growth and prosperity in countries. These positive effects of the level of legal institutional quality tend to be more relevant and significant in low-income countries with relatively weaker institutions.

Keywords: Legal Institutions. Economic Growth. Rule of Law. Panel VAR.

\section{SUMÁRIO}

INTRODUÇÃO 1. QUALIDADE DAS INSTITUIÇÕES, ESTADO DE DIREITO E CRESCIMENTO ECONÔMICO 1.1 Definindo Instituiçôes Jurídicas 1.2 Estado de Direito e Qualidade das Instituiçôes Jurídicas 1.3 Qualidade das Instituiçôes Jurídicas e Crescimento Econômico 2. MENSURANDO OS EFEITOS DA QUALIDADE INSTITUCIONAL JURÍDICA SOBRE O CRESCIMENTO ECONÔMICO DOS PAÍSES 3. RESULTADOS 3.1 Base de Dados 3.2 Resultados da Estimaçáo do Modelo de Qualidade das Instituições Jurídicas e Crescimento Econômico CONSIDERAÇÕES FINAIS

\section{INTRODUÇÁO}

As instituições, em sua mais ampla e aceita dimensão conceitual, correspondem às restrições humanamente concebidas, que moldam a interação política, econômica e social. Ao longo da história, as instituiçóes foram criadas com a finalidade de estabelecer ordem e reduzir a incerteza. North ${ }^{1}$, ao estabelecer essa definição, entende que as instituições formam um conjunto de regras informais, provenientes da tradição, do código de conduta, do costume, do tabu e das sançóes; e de regras formais, que compóem as leis, as constituiçóes e os direitos de propriedade.

Ao enfatizar o papel desempenhado pelas instituições, North ${ }^{2}$ argumenta que algumas economias desenvolvem instituições que promovem crescimento, enquanto outras economias desenvolvem instituiçóes que produzem declínio.

As instituições que interessam a este trabalho correspondem ao conjunto de regras jurídicas formais que influenciam e moldam as escolhas e decisóes no âmbito do desempenho econômico dos países, tanto na dimensão microeconômica quanto macroeconômica.

A existência de instituições jurídicas fortes propicia uma estrutura legal efetiva, além de segurança contratual e mecanismos de resolução de disputas que favorecem o crescimento

NORTH, Douglass Cecil. Institutions. Journal of Economic Perspectives, p. 97-112, 1991.

2 NORTH, Douglass Cecil. Structure and change in economic history. Norton, 1981. 
e o desenvolvimento econômico dos países. Ademais, instituiçóes jurídicas consistentes com os direitos humanos podem proporcionar um desenvolvimento que também seja inclusivo e sustentável. A proteção dos direitos de propriedade depende também de instituições jurídicas fortes e de um sistema jurídico que funcione de forma efetiva.

Do ponto de vista da teoria econômica, as instituiçóes jurídicas fortes criam uma estrutura de incentivos em uma economia, enquanto que as instituiçóes jurídicas fracas resultam em desincentivos. Assim, as instituiçôes determinam a viabilidade da atividade econômica, influenciando os custos de produção e de transação. Neste contexto, é possível observar que, em países que apresentam instituições jurídicas mais fortes, as empresas são maiores e mais eficientes, uma vez que essas empresas enfrentam menos riscos inerentes à insegurança jurídica e um ambiente de negócios com menor incerteza, resultando em maior acesso ao crédito e expansão dos investimentos.

Por outro lado, em países que possuem instituiçóes jurídicas mais fracas, observa-se que muitas empresas deixam de investir nessas regióes devido à falta de confiança e segurança nesse arcabouço institucional, incapaz de garantir os direitos de propriedade, o cumprimento de contratos e a credibilidade necessária ao acesso ao crédito. Dessa forma, a fraqueza institucional jurídica se traduz em baixo crescimento econômico. Portanto, em países onde as instituições jurídicas são consideradas fracas, a segurança jurídica, a credibilidade e a confiança que as pessoas têm no sistema jurídico são baixas, aumentando significativamente o risco das atividades econômicas e, consequentemente, reduzindo a propensão a investir das empresas. Logo, um arcabouço institucional jurídico fraco pode gerar, muitas vezes, desincentivos ou incentivos distorcidos para uma economia.

No decorrer das duas últimas décadas, um número considerável de pesquisas foi desenvolvido com vistas a demonstrar a existência de uma forte correlação entre a origem histórica das leis e instituiçóes e o desempenho econômico dos países. Neste sentido, La Porta, Lopez-de-Silanes e Shleifer ${ }^{3}$ sintetizam essas evidências e buscam mostrar que a contribuição básica desses trabalhos parece ser confirmada pelas pesquisas recentes: a ideia de que as origens legais, amplamente interpretadas como sistemas altamente persistentes, trazem consequências significativas para a atual estrutura jurídica da sociedade, influenciando o desenvolvimento e crescimento econômico dos países.

Considerando a importância de se incorporar a análise institucional no estudo do desempenho econômico dos países, o objetivo principal deste trabalho consiste em investigar como a qualidade das instituiçóes jurídicas afeta o desempenho econômico dos países.

Desse modo, buscou-se analisar a relação existente entre o nível de qualidade das instituições jurídicas e o desempenho econômico de um conjunto de 118 países, em um período de 15 anos, compreendido entre os anos de 2002 a 2016. Para tanto, foi desenvolvido um modelo econométrico capaz de captar os efeitos de uma melhoria - choque positivo - na qualidade das instituiçóes jurídicas sobre a trajetória futura do desempenho econômico dos países. Ademais, observou-se como esses efeitos variam de acordo com o nível de renda dos países.

LA PORTA, Rafael; LOPEZ-DE-SILANES, Florencio; SHLEIFER, Andrei. The economic consequences of legal origins. Journal of Economic Literature, p. 285-332, 2008. 
A qualidade das instituições jurídicas está intrinsecamente relacionada à efetividade das regras e normas que compóe o arcabouço jurídico vigente em um país, e ao comprometimento do governo e dos cidadãos em cumprir as regras estabelecidas, possibilitando classificá-las como instituições fortes ou fracas. Assim, conforme destaca Aoki ${ }^{4}$, uma nova regra que náo consegue deslocar as expectativas dos agentes no sentido de se comprometerem a cumpri-la pode não ter efeito algum, sendo assim considerada demasiadamente fraca. Neste sentido, uma regra que restrinja ou estabeleça um determinado comportamento será efetiva somente se os indivíduos esperarem que os demais agentes (incluindo os responsáveis por fazer cumprir a regra) atuem de forma a torná-la forte e efetiva.

Ao corroborar essa ideia, Dam ${ }^{5}$ argumenta que nenhuma melhoria substantiva da lei trará o Estado de Direito a um país sem a sua aplicação efetiva. Assim, a existência de instituições jurídicas fortes é fundamental para a efetividade do Judiciário. O Estado de Direito reflete, portanto, o nível de qualidade das instituiçóes jurídicas vigentes em um país.

$\mathrm{Na}$ análise empírica deste trabalho, o indicador de governança do Banco Mundial, denominado Rule of Law, foi utilizado como variável representativa da qualidade das instituiçóes jurídicas. Esse indicador é conceitualmente adequado para esta análise, uma vez que busca captar a percepção do nível de confiança e de cumprimento das regras que moldam uma sociedade, em especial, o nível de qualidade da execução dos contratos, dos direitos de propriedade, da polícia e dos tribunais.

Os resultados das estimaçóes mostraram que um choque de melhoria na qualidade das instituiçóes jurídicas gera efeitos positivos sobre o PIB per capita no período imediatamente posterior ao choque. Ao analisar os resultados relativos ao grupo de países de renda alta, observou-se que os efeitos de uma melhoria da qualidade institucional jurídica sobre o crescimento econômico são significativamente menores do que os efeitos médios encontrados na estimação da amostra de países de baixa renda.

Assim, é possível inferir que esses resultados estão de acordo com a hipótese de convergência de renda. Neste contexto, pode-se considerar que países que apresentam maior nível de renda, em geral, possuem instituiçóes jurídicas mais fortes e, consequentemente, os efeitos de melhorias da qualidade dessas instituiçóes geram menor impacto sobre o crescimento econômico desses países se comparados com países de baixa renda. Logo, os efeitos de um choque de melhoria da qualidade institucional jurídica tendem a ser mais relevantes e significativos em países de baixa renda que apresentam instituiçóes relativamente mais fracas.

Este artigo pretende contribuir para a literatura empírica na medida em que incorpora o papel da qualidade das instituiçóes jurídicas na análise do desempenho econômico dos países, por meio da utilização de uma metodologia empírica ainda pouco explorada para analisar tal questão.

\footnotetext{
4 AOKI, Masahiko. Towards a Comparative Institutional Analysis. MIT Press, 2001.

5 DAM, Kenneth W. The judiciary and economic development. U Chicago Law \& Economics, Olin Working Paper, n. 287, 2006.
} 
O artigo está organizado da seguinte forma. A primeira seção traz os principais conceitos e relaçôes existentes entre Estado de Direito, qualidade das instituições jurídicas e crescimento econômico, fundamentais para uma melhor compreensão dos resultados desta pesquisa. Na segunda seção, há uma descrição da metodologia empírica utilizada para mensurar os efeitos da qualidade institucional jurídica sobre o crescimento econômico dos países. A terceira seção apresenta os resultados estimados e a última seção contém as considerações finais deste estudo.

\section{QUALIDADE DAS INSTITUIÇÓES, ESTADO DE DIREITO E CRESCI- MENTO ECONÔMICO}

\subsection{Definindo Instituiçóes Jurídicas}

North ${ }^{6}$ conceitua as instituiçóes como as regras do jogo concebidas em uma sociedade, a partir da seguinte definição:

Instituições são restrições humanamente concebidas que estruturam as interaçôes políticas, econômicas e sociais. Consistem tanto em restriçôes informais (sanções, tabus, costumes, tradiçôes, e códigos de conduta), quanto em restriçóes formais (constituições, leis, direitos de propriedade). ${ }^{7}$

Nessa perspectiva, as instituiçóes representam para os indivíduos um conjunto de restriçóes às suas ações, estabelecidas pela própria sociedade ou por organizaçóes, como o Estado. Tais restriçôes podem ser formais, como as leis e as constituições, ou podem ser informais, provenientes de costumes e tradiçóes de uma sociedade.

Seguindo a essência do conceito amplo defendido por $\mathrm{North}^{8}$, as instituiçóes jurídicas correspondem a um conjunto de regras jurídicas que disciplinam as relaçóes entre os indivíduos, cuja obediência e o cumprimento são exigidos de toda a sociedade. Assim, as instituiçóes jurídicas constituem verdadeiros tratados de ordem geral e abstrata, sendo confirmadas, a partir do fenômeno jurídico da positivação, por meio das normas válidas e vigentes que compóem o ordenamento jurídico, um amplo e complexo sistema interligado, conforme define Bobbio ${ }^{9}$ em sua conclusão a respeito da teoria da instituição:

A nosso ver, a teoria da instituição teve o grande mérito de pôr em relevo o fato de que se pode falar de Direito somente onde haja um complexo de normas formando um ordenamento, e que, portanto, o Direito não é norma, mas um conjunto coordenado de normas, sendo evidente que uma norma jurídica não se encontra jamais só, mas está ligada a outras normas com as quais forma um sistema normativo. ${ }^{10}$

\footnotetext{
NORTH, Douglass Cecil. Institutions. Journal of Economic Perspectives, p. 97-112, 1991.

Id., Op. Cit. (1991).

$8 \quad$ Id., Op. Cit. (1991).

9 BOBBIO, Norberto. Teoria da norma jurídica, 2001.

10 Id., Op. Cit.
} 
As instituições que interessam a este trabalho correspondem ao conjunto de regras jurídicas formais que influenciam e moldam as escolhas e decisóes no âmbito do desempenho econômico dos países, tanto na dimensão microeconômica quanto macroeconômica ${ }^{11}$. As instituiçôes criam uma estrutura de incentivos e desincentivos em uma economia, determinando assim a viabilidade da atividade econômica, uma vez que elas influenciam diretamente os custos de produção e de transação. Dessa forma, algumas economias desenvolvem instituiçóes que promovem crescimento e desenvolvimento, enquanto outras desenvolvem instituiçóes que produzem declínio e estagnaçáo.

As instituições jurídicas, resultantes das organizações e interações humanas, são passíveis de mudanças. $\mathrm{Na}$ análise empírica deste trabalho, consideramos a possibilidade de mudança institucional, refletindo em diferentes níveis de qualidade das instituições jurídicas ao longo do tempo. Dessa forma, nos referimos ao que Roland ${ }^{12}$ denomina de instituiçóes políticas "fast moving", correspondendo às regras formais que podem ser alteradas de forma rápida e deliberada por meio de um processo político centralizado. Roland ${ }^{13}$ distingue essas instituiçôes políticas das instituiçôes culturais "slow moving", que consistem nas regras informais que mudam lentamente, de forma contínua, evolutiva e descentralizada. Sendo assim, a mudança institucional é tratada como um processo político centralizado, por meio do qual as regras são explicitamente estabelecidas e alteradas por uma entidade política coletiva: o governo.

\subsection{Estado de Direito e Qualidade das Instituiçóes Jurídicas}

Annan ${ }^{14}$ descreveu o Estado de Direito como um princípio de governança segundo o qual todas as pessoas, instituiçóes e entidades, públicas e privadas, incluindo o próprio Estado, são responsáveis por leis que são publicamente promulgadas, igualmente aplicadas e adjudicadas independentemente, sendo consistentes com as normas e padróes internacionais de direitos humanos. Neste sentido, as nações devem adotar medidas que visem garantir a aderência aos princípios da supremacia, igualdade, responsabilidade e justiça na aplicação da lei, separação de poderes, participação na tomada de decisóes, segurança jurídica, prevenção, arbitrariedade e transparência processual e jurídica.

Em consonância com essa definição estabelecida por Annan ${ }^{15}, \operatorname{Dam}^{16}$ sintetizou três ideias

\footnotetext{
11 A dimensão microeconômica abrange o comportamento individual dos agentes econômicos, ou seja, dos consumidores, das empresas e dos mercados nos quais esses agentes interagem entre si. Já a dimensáo macroeconômica reflete o comportamento do sistema econômico em seu conjunto, de forma agregada. 12 ROLAND, Gerard. Understanding Institutional Change: Fast-moving and Slow-moving institutions. Studies in Comparative International Development, 2004, p.109-131.

13 Id., Op. Cit.

14 ANNAN, Kofi. The rule of law and transitional justice in conflict and post-conflict societies. Report of the Secretary-General, 2004.

15 ANNAN, Kofi. The rule of law and transitional justice in conflict and post-conflict societies. Report of the Secretary-General, 2004.

16 DAM, Kenneth W. The judiciary and economic development. U Chicago Law \& Economics, Olin Working Paper, n. 287, 2006.
} 
intrínsecas ao Estado de Direito, quais sejam:

i. As regras legais devem ser escritas e disponibilizadas a todos os residentes de um país: nenhuma lei secreta.

ii. As regras devem ser aplicadas e cumpridas de forma igual e imparcial para todos, independentemente da posição ou status: ninguém está acima da lei.

iii. Os indivíduos devem ter o direito de ter regras que os favoreçam e beneficiem. Em outras palavras, eles têm direito ao acesso à justiça de forma não discriminatória, não importando quem eles sejam e quem seja o réu: igualdade de acesso à justiça.

Em sua forma mais simples, o Estado de Direito pode ser entendido como um sistema sob o qual as relaçóes entre os cidadãos, e desses com o governo, são regidas por leis que devem ser seguidas e aplicadas. No Estado de Direito, as leis precisam ser acessíveis, aplicáveis e compreensíveis. As regras devem ser cumpridas e, garantindo o devido processo legal, devem conceder aos cidadãos seus direitos fundamentais e regular as suas relaçóes de maneira justa.

O Estado de Direito desempenha um papel fundamental na consolidação e garantia dos direitos econômicos e sociais nas constituiçóes, leis e normas vigentes em um país. Ao fornecer os meios de reparação quando esses direitos não são mantidos e apoiar a sua efetividade por meio da implementação de políticas e programas nacionais. Além disso, as instituiçóes do Estado de Direito contribuem para garantir que a aplicação dessas políticas esteja em conformidade com a lei e seja exercida de forma não discriminatória.

Portanto, a essência do estado de direito consiste na soberania ou supremacia da lei sobre pessoas e governos. Neste sentido, Watson ${ }^{17}$ destaca que o estado de direito é mais do que o seu regulamento por lei, mas uma garantia de liberdades, direitos humanos e igualdade de tratamento perante a lei.

Todavia, existem diferentes definiçóes de Estado de Direito, decorrentes das histórias sociopolíticas, jurídico-institucionais e dos ideais normativos que caracterizam as sociedades ao longo do tempo. Nesse sentido, Krygier ${ }^{18}$ destaca que as definições ainda podem variar em termos de forma, ou seja, como as instituições do estado de direito devem ser moldadas; e função, isto é, a que propósito as instituiçóes devem servir.

No que diz respeito aos elementos de forma, é possível observar variações com relação à separação de poderes, revisão judicial e constitucional, resoluçóes de disputas, assim como órgáos reguladores e uma variedade de proteçóes de direitos humanos. $\mathrm{O}$ estado de direito considera a capacidade dos indivíduos de acessar a lei, por meio do fornecimento de diferentes formas de suporte, com destaque para a assistência jurídica, e canalização

17 WATSON, P. The Rule of Law and Economic Prosperity, 2003.

18 KRYGIER, M. Rule of law. In: WRIGHT, JD (Ed.) Encyclopedia of the Social and Behavioral Sciences. $2^{\text {nd, }}$. Atlanta, GA: Elsevier, 2015. pp. 45-59. 
de informações sobre direitos e justiça e responsabilização dos governantes, por meio do acesso à informação, conscientização e conhecimento sobre como o poder e os direitos são defendidos, distribuídos e regulados.

Já o elemento funcional do estado de direito consiste em uma variedade de fins pretendidos. Em essência, o Estado de Direito trata da capacidade política e institucional de impor limites acordados ao exercício do poder e de resolver disputas sobre a alocação de poder e de recursos por meios não violentos. Contudo, conforme o arcabouço institucional jurídico de cada país, há extensóes de diferentes dimensões desses atributos, que estão relacionados à capacidade de implementar mecanismos efetivos de controle, resolver disputas, administrar e garantir os direitos, conforme definidos na estrutura normativa vigente.

De acordo com Krygier ${ }^{19}$, o Estado de Direito nunca é absoluto, sendo melhor compreendido como um processo no qual qualidades e práticas desiguais tendem a coexistir. É possível notar diferenças até mesmo entre grupos de uma mesma sociedade, refletindo a natureza das relaçóes de poder e das desigualdades estruturais. Esse comportamento pode ser observado inclusive em democracias consolidadas, que apresentam ordens legais, judiciais e policiais estáveis, naqueles lugares onde há uma significativa resistência das elites em se vincular à lei, cujos interesses concorrentes na prática resultam em direitos de algumas pessoas que superam os direitos de outras.

Dam $^{20}$ argumenta que nenhuma melhoria substantiva da lei trará o Estado de Direito a um país sem a sua aplicação efetiva. A existência de instituições jurídicas fortes é fundamental para a efetividade do Judiciário. O Estado de Direito reflete, portanto, o nível de qualidade das instituiçóes jurídicas vigentes em um país.

A qualidade das instituições jurídicas está intrinsecamente relacionada à efetividade das regras e normas que compóe o arcabouço jurídico vigente em um país, e ao comprometimento do governo e dos cidadãos em cumprir as regras estabelecidas, possibilitando classificá-las como instituiçóes fortes ou fracas. Assim, conforme destaca Aoki ${ }^{21}$, uma nova regra que não consegue deslocar as expectativas dos agentes no sentido de se comprometerem a cumpri-la pode não ter efeito algum, sendo assim considerada demasiadamente fraca. Neste sentido, uma regra que restrinja ou estabeleça um determinado comportamento será efetiva somente se os indivíduos esperarem que os demais agentes (incluindo os responsáveis por fazer cumprir a regra) atuem de forma a torná-la forte e efetiva.

\subsection{Qualidade das Instituiçóes Jurídicas e Crescimento Econômico}

Ao longo das duas últimas décadas, um número considerável de pesquisas foi desenvolvido com vistas a demonstrar a existência de uma forte correlação entre a origem histórica

19 KRYGIER, M. Rule of law. In: WRIGHT, JD (Ed.) Encyclopedia of the Social and Behavioral Sciences. $2^{\text {ndd }}$. Atlanta, GA: Elsevier, 2015. pp. 45-59.

20 DAM, Kenneth W. The judiciary and economic development. U Chicago Law \& Economics, Olin Working Paper, n. 287, 2006.

21 AOKI, Masahiko. Towards a Comparative Institutional Analysis. MIT Press, 2001. 
das leis e o desempenho econômico dos países. Neste sentido, La Porta, Lopez-de-Silanes e Shleifer ${ }^{22}$ sintetizam essas evidências e buscam mostrar que a contribuição básica desses trabalhos parece ser confirmada pelas pesquisas recentes: a ideia de que as origens legais, amplamente interpretadas como sistemas altamente persistentes, trazem consequências significativas para a atual estrutura legal e reguladora da sociedade, influenciando o desenvolvimento e crescimento econômico dos países. Com base nessa análise, esses autores desenvolvem quatro importantes proposiçóes, quais sejam: (i) as instituiçóes jurídicas diferem sistematicamente entre os países, e essas diferenças podem ser medidas e quantificadas; (ii) essas diferenças nas regras e regulamentos legais são explicadas em grande parte pelas origens legais; (iii) a divergência histórica básica nos estilos de tradições jurídicas explica bem por que as regras legais diferem; e (iv) as instituiçóes jurídicas são importantes para os resultados econômicos e sociais.

O nível de qualidade das instituições jurídicas não está associado apenas à necessidade de uma justiça efetiva, sendo ainda fundamental para o desenvolvimento econômico dos países. A literatura empírica que investiga a relação entre a qualidade das instituiçóes jurídicas e o desempenho econômico dos países têm demonstrado efeitos positivos da efetividade das instituiçóes jurídicas sobre o crescimento econômico. Neste sentido, países que possuem instituições jurídicas fortes e efetivas, em geral, apresentam um crescimento mais significativo da atividade econômica. Nesses países, há uma elevada efetividade das regras e normas que compóe o arcabouço jurídico, e um forte comprometimento do governo e dos cidadãos em cumprir as regras estabelecidas.

A existência de instituiçóes jurídicas fortes propicia uma estrutura legal efetiva, além de segurança contratual e mecanismos de resolução de disputas que favorecem o crescimento e o desenvolvimento econômico dos países. Ademais, instituiçóes jurídicas consistentes com os direitos humanos podem proporcionar um desenvolvimento que também seja inclusivo e sustentável. A proteção dos direitos de propriedade depende também de instituiçôes jurídicas fortes e de um sistema jurídico que funcione de forma efetiva.

Do ponto de vista da teoria econômica, as instituiçóes jurídicas fortes criam uma estrutura de incentivos em uma economia, enquanto que instituiçóes jurídicas fracas resultam em desincentivos. Assim, as instituições determinam a viabilidade da atividade econômica, influenciando os custos de produção e de transação. Neste contexto, é possível observar que, em países que apresentam instituiçóes jurídicas mais fortes, as empresas são maiores e mais eficientes, uma vez que essas empresas enfrentam menos riscos inerentes à insegurança jurídica e um ambiente de negócios com menor incerteza, resultando em maior acesso ao crédito e expansão dos investimentos.

Por outro lado, em países que possuem instituiçóes jurídicas mais fracas, observa-se que muitas empresas deixam de investir nessas regióes devido à falta de confiança e segurança nesse arcabouço institucional, incapaz de garantir os direitos de propriedade, o cumprimento de contratos e a credibilidade necessária ao acesso ao crédito. Dessa forma, a fraqueza institucional jurídica se traduz em baixo crescimento econômico. Portanto, em

LA PORTA, Rafael; LOPEZ-DE-SILANES, Florencio; SHLEIFER, Andrei. The economic consequences of legal origins. Journal of Economic Literature, p. 285-332, 2008. 
países onde as instituições jurídicas são consideradas fracas, a segurança jurídica, a credibilidade e a confiança que as pessoas têm no sistema jurídico são baixas, aumentando significativamente o risco das atividades econômicas e, consequentemente, reduzindo a propensão a investir das empresas. Logo, um arcabouço institucional jurídico fraco pode gerar, muitas vezes, desincentivos ou incentivos distorcidos para uma economia.

Além de desestimular investimentos e a utilização de capital disponível; reduzir a atividade econômica, desestimulando a especialização e dificultando a exploração de economias de escala; a fraqueza institucional pode ainda distorcer o sistema de preços, ao considerar fontes de riscos adicionais ao ambiente de negócios, e diminuir a efetividade das políticas macroeconômicas.

É importante observar ainda a existência de uma relação entre a atividade econômica e o atraso dos tribunais na resolução de casos: o tempo necessário para resolver um processo aumenta a incerteza entre os agentes econômicos, dificultando as transaçóes nos mercados. Os sistemas judiciais têm em todo o mundo a tarefa de fazer cumprir a lei, tornando regimes regulatórios institucionais efetivos. Johnson et al. ${ }^{23}$, Chemin ${ }^{24}$ e Ippoliti et al. ${ }^{25}$ corroboram a ideia de que esse ambiente de segurança jurídica desempenha um papel fundamental para o crescimento econômico dos países, uma vez que sistemas jurídicos efetivos estimulam o estabelecimento de novas relaçóes comerciais e reduz barreiras de entrada no mercado, o que torna os mercados mais dinâmicos.

O judiciário consiste no principal instrumento por meio do qual os agentes econômicos resolvem suas disputas. Sendo assim, um sistema jurídico efetivo tem a capacidade de reduzir a incerteza inerente às transaçóes econômicas.

Portanto, é possível observar que entre as instituiçóes que geram impactos significativos sobre o desempenho econômico dos países, as instituiçóes jurídicas desempenham um papel relevante. Compreender como a qualidade das instituiçóes jurídicas vigentes afeta o desempenho econômico de um país permite identificar a estrutura de incentivos e desincentivos que norteia o crescimento e desenvolvimento econômico dos países. A qualidade do arcabouço institucional jurídico pode influenciar a atividade econômica por meio da alocaçáo de recursos, da produtividade dos fatores e das decisóes sobre investimentos.

Os principais canais por meio do qual a baixa qualidade das instituiçóes afeta o desempenho econômico são: o investimento, o progresso tecnológico, a eficiência das firmas e a qualidade da política econômica.

O progresso tecnológico é bastante influenciado pela qualidade institucional, uma vez que são as instituiçóes jurídicas que garantem o direito de propriedade intelectual. Nos países em que essas instituições são fortes e efetivas, o respeito à propriedade intelectual

23 JOHNSON, S., MCMILLAN, J., WOODRUFF, C. Courts and Relational Contracts. Journal of Law, Economics, and Organization, p.221-277, 2002.

24 CHEMIN, M. The impact of the judiciary on entrepreneurship: Evaluation of Pakistan's "Access to Justice Programme”. Journal of Public Economics, Amsterdam, p.114-125, 2009.

25 IPPOLITI, R.; MELCARNE, A.; RAMELLO, G. B. Judicial eciency and entrepreneurs' expectations on the reliability of European legal systems. European Journal of Law and Economics, p.75-94, 2015. 
estimula o investimento em pesquisa e desenvolvimento e propicia a aquisição de tecnologia avançada de outros países.

No que diz respeito à eficiência das empresas, observa-se que, a existência de instituiçóes fracas prejudica a garantia e a manutenção dos contratos, desestimulando assim a expansão de negócios pelas empresas, que acabam deixando de explorar economias de escala, além de alocarem seus recursos de forma ineficiente. Além disso, há uma maior tendência à verticalização das empresas com a presença de instituiçóes fracas que não garantem a execuçáo d os contratos. Dessa forma, concentram-se em uma única empresa atividades que poderiam ser desenvolvidas de forma mais eficiente por empresas especializadas.

A efetividade das políticas econômicas também é influenciada pela qualidade das instituiçóes jurídicas. Acemoglu et al. ${ }^{26}$ demonstraram que a qualidade institucional de um país exerce um papel importante no desempenho das políticas macroeconômicas. Esses autores defendem a ideia de que países que adotam políticas econômicas ineficazes e distorcidas, em geral, possuem instituiçóes econômicas e jurídicas fracas, que não limitam o poder dos políticos e elites, além de aplicarem os direitos de propriedade de forma ineficaz, apresentarem corrupção generalizada e elevado grau de instabilidade política e insegurança jurídica. Essa perspectiva considera que o desempenho econômico de muitos países pode refletir as causas institucionais profundas que levam a políticas econômicas distorcidas. Ou seja, a condução de políticas econômicas distorcidas é um sintoma de problemas institucionais subjacentes dos países.

Em síntese, uma estrutura institucional forte e efetiva garante que as transações econômicas sejam realizadas de forma segura e com custos mais baixos. Além disso, reduz a ineficiência na alocação de recursos, por meio da combinação de estabilidade institucional, econômica e política. Assim, um arcabouço institucional jurídico forte contribui para o crescimento econômico ao prover o uso eficiente de recursos em áreas produtivas.

\section{MENSURANDO OS EFEITOS DA QUALIDADE INSTITUCIONAL JURÍDI- CA SOBRE O CRESCIMENTO ECONÔMICO DOS PAÍSES}

O objetivo principal deste trabalho consiste em investigar a relação existente entre o nível de qualidade das instituiçóes jurídicas e o desempenho econômico de um conjunto de 118 países, em um período de 15 anos, compreendido entre os anos de 2002 a 2016. Seguindo a metodologia utilizada por Góes ${ }^{27}$ e Gadelha e Divino ${ }^{28}$, desenvolveu-se um modelo econométrico capaz de captar os efeitos de uma melhoria - choque positivo - na

\footnotetext{
26 ACEMOGLU, D., JOHNSON, S., ROBINSON, J.A. Institutional causes, macroeconomic symptoms: volatility, crises and growth. Journal of monetary economics, Amsterdam, p. 49-123, 2003.

27 GÓES, Carlos. Institutions and growth: A GMM/IV panel VAR approach. Economics Letters, Amsterdam, p. 85-91, 2016.

28 GADELHA, A.; DIVINO, J. A. Institutions, growth and economic stability. Economics Bulletin, p. 554-563, 2019.
} 
qualidade das instituiçóes jurídicas sobre a trajetória futura do desempenho econômico dos países. Ademais, buscou-se analisar como esses efeitos variam de acordo com o nível de renda dos países.

Em que pese a vasta literatura empírica que investiga a relação entre instituiçóes e crescimento econômico, este artigo utiliza uma metodologia ainda pouco explorada para analisar tal questáo. Este trabalho segue uma abordagem macroeconométrica, a partir da estimação de vetores autorregressivos para dados em painel (Panel Vector Autoregressive $P V A R)$, com vistas a analisar as relaçóes dinâmicas existentes entre qualidade das instituiçóes jurídicas e crescimento econômico dos países.

Tendo em vista a complexa rede de causalidade que envolve essas duas variáveis - qualidade das instituiçóes jurídicas e desempenho econômico - considera-se a modelagem PVAR a mais adequada para o desenvolvimento deste trabalho. Nos modelos PVAR, todas as variáveis são consideradas endógenas e interdependentes, tratando a heterogeneidade individual não observada e específica de cada país que compóe o painel por meio de efeitos fixos.

A aplicação dessa metodologia tem como objetivo estimar funçôes impulso-resposta com vistas a evidenciar os efeitos sobre uma variável endógena de um choque em outra variável do sistema. As funçóes impulso-resposta têm sido o cerne das análises que utilizam a metodologia PVAR, com vistas a obter os efeitos de choques sobre a trajetória futura de qualquer uma das variáveis do modelo.

Utilizando dados em painel e incluindo efeitos fixos, evita-se o risco dos resultados serem influenciados por características não observadas dos países. ${ }^{29}$

A relação dinâmica entre as variáveis endógenas do modelo empírico pode ser descrita da seguinte forma:

$$
\begin{aligned}
Y_{i, t}=A_{o i}+A(l) \cdot Y_{i, t-j}+f_{i} & +u_{i, t} \\
\mathrm{i} & =\{1, \ldots 118\} \text { e } \mathrm{t}=\{2002, \ldots 2016\}
\end{aligned}
$$

Onde:

$Y_{i, t}=\left\{X_{i, t}, I_{i, t}\right\}$

$Y_{i, t-j}=\left\{X_{i, t-j}, I_{i, t-j}\right\}$, onde $\mathrm{j}=1,2, \ldots, \mathrm{p}$

$A_{0 i}=$ matriz diagonal de interceptos invariantes no tempo.

$A(l)=$ matrizes de coeficientes defasados.

$Y_{i, t}=$ vetores de variáveis endógenas contemporâneas

$X_{i, t}=$ desempenho macroeconômico do país i no período t.

\footnotetext{
29 A solução padrão para este problema consiste geralmente em incluir variáveis de controle; no entanto, neste contexto, determinantes relevantes do crescimento econômico, como a cultura, são difíceis de mensurar. Dessa forma, a presença de efeitos fixos controla as características invariantes no tempo de todos os países, tais como: geografia, clima, religião, cultura e história. Sendo assim, a utilização do PVAR contorna problemas relacionados a variáveis omitidas e causalidade reversa.
} 
$I_{i, t}=$ qualidade das instituiçôes jurídicas do país i no período t.

$Y_{i, t-j}=$ vetores de variáveis endógenas defasadas.

$f_{i}=$ efeitos fixos

$u_{i, t}=$ vetor de erros aleatórios.

Neste modelo PVAR, $Y_{i, t}$ e $Y_{i, t-j}$ correspondem aos conjuntos de vetores de variáveis endógenas contemporâneas e defasadas, respectivamente; $f_{i}$ é o efeito fixo não observado e $u_{i, t}$ consiste no vetor de erros aleatórios. As matrizes $A(l)$ captam os efeitos próprios e cruzados das variáveis defasadas sobre suas observaçôes contemporâneas.

$\mathrm{O}$ vetor $X_{i, t}$ é constituído por séries variantes no tempo e entre países, representativas do desempenho econômico, em que $X_{i, t}=$ Log do PIB per capita anual. O vetor $I_{i, t}$ corresponde à série do indicador representativo da qualidade das instituiçóes jurídicas.

\section{RESULTADOS}

\subsection{Base de Dados}

Com vistas a investigar a relação existente entre qualidade das instituições jurídicas e crescimento econômico de um conjunto de 118 países, no período de 2002 a 2016, serão utilizadas as seguintes séries temporais em painel balanceado, com periodicidade anual:

I. PIB per capita como variável representativa do desempenho econômico dos países: logaritmo do PIB per capita anual (preços constantes de 2010, US\$).

II. Rule of Law como variável representativa da Qualidade das Instituiçôes Jurídicas: Desenvolvido conforme metodologia descrita em Kaufmann et al. ${ }^{30}$, o indicador está em unidades de distribuição normal padrão $(\mu=0 ; \sigma=1)$, com valores mais altos correspondendo à melhor qualidade das instituiçôes jurídicas.

As séries ${ }^{31}$ temporais foram extraídas do banco de dados do Banco Mundial e cada variável apresenta um total de 1.770 observaçôes. As estatísticas descritivas das séries temporais em painel, referentes a essas duas variáveis, a serem utilizadas nos modelos econométricos, estão sintetizadas na Tabela a seguir:

30 KAUFMANN, Daniel; KRAAY, Aart; MASTRUZZI, Massimo. The worldwide governance indicators: methodology and analytical issues. Hague Journal on the Rule of Law, p. 220-246, 2011.

31 O requisito de estacionariedade das séries temporais utilizadas na estimação do modelo foi verificado mediante a realização de testes de raiz unitária. Os resultados dos testes demonstraram que as séries a serem utilizadas nas estimaçóes são estacionárias. A estabilidade dos modelos foi verificada mediante a análise das raízes inversas do polinômio característico autorregressivo. Todas as raízes dos sistemas de equaçóes estimados encontraram-se dentro do círculo unitário, logo, a condição de estabilidade dos modelos foi satisfeita. 
Tabela 1: Estatísticas Descritivas das Variáveis do Modelo PVAR

\begin{tabular}{cccccc}
\hline Variável & Observaçóes & Média & Desv. Padrão & Mínimo & Máximo \\
\hline \hline $\begin{array}{c}\text { Indicador de } \\
\text { Qualidade das } \\
\text { Instituições } \\
\text { Jurídicas }\end{array}$ & 1.770 & 0,0014 & 1,0000 & $-1,8431$ & 2,1003 \\
\hline $\begin{array}{c}\text { PIB per capita } \\
\text { (US\$) }\end{array}$ & 1.770 & $13.258,01$ & $19.275,09$ & 177,82 & $119.172,70$ \\
\hline
\end{tabular}

Fonte: Elaboração própria a partir de dados do Banco Mundial, com a utilização do software estatístico Stata.

Nesta análise empírica, a série representativa do crescimento econômico foi transformada em logaritmos, com vistas a tornar mais clara a interpretação dos resultados.

O indicador de governança Rule of Law foi utilizado como variável representativa da qualidade das instituições jurídicas. É importante ressaltar que essa variável não é representativa do arcabouço institucional em si, mas do nível de qualidade das instituiçóes vigentes nos países. Esse nível de qualidade das instituições está intrinsecamente relacionado à efetividade das regras e normas jurídicas vigentes e ao comprometimento dos cidadãos em cumprir as metas e regras estabelecidas.

O indicador de governança Rule of Law é conceitualmente adequado para esta análise, uma vez que busca captar a percepção do nível de confiança e de cumprimento das regras que moldam a sociedade, em especial, o nível de qualidade da execução dos contratos, dos direitos de propriedade, da polícia e dos tribunais. Teoricamente, espera-se uma sociedade que seja efetivamente capaz de executar suas políticas de crescimento econômico mediante um arcabouço institucional forte e sólido.

A utilização do indicador Rule of Law como representativo do nível de qualidade das instituiçôes jurídicas fundamenta-se na ideia de que países que apresentam instituiçóes jurídicas fracas, em geral, são incapazes de lidar de forma apropriada com períodos de incerteza, instabilidades e desaceleraçóes econômicas, decorrentes de crises internas e externas. Consequentemente, maior nível de qualidade das instituições jurídicas implica menor instabilidade, criando um ambiente propicio para o crescimento econômico.

\subsection{Resultados da Estimaçáo do Modelo de Qualidade das Instituiçóes Jurídicas e Crescimento Econômico}

As funções impulso-resposta estimadas pelo modelo VAR em painel evidenciaram os efeitos de um choque na variável de interesse sobre a trajetória futura das demais variáveis do modelo, após controlar características dos países invariantes no tempo.

Um choque na variável representativa da qualidade das instituiçóes jurídicas corresponde a uma inovação, uma melhoria da qualidade institucional. Os resultados indicam que 
melhorias na qualidade das instituições jurídicas vigentes em um país podem levar a um aumento do PIB per capita, o que também pode ser observado na correlação contemporânea positiva entre as duas variáveis, conforme pode ser visto na Figura 1.

Considerando que a correlação contemporânea demonstrada na Figura 1 gera dinâmicas homogêneas e resultados médios para todos os países da amostra, a amostra será dividida em grupos de países com o intuito de estimar e analisar como os efeitos da qualidade das instituiçóes sobre o crescimento econômico variam de acordo com o nível de renda dos países.

\section{Figura 1: Correlação Contemporânea entre a qualidade das instituiçóes jurídicas e o crescimento do PIB per capita}

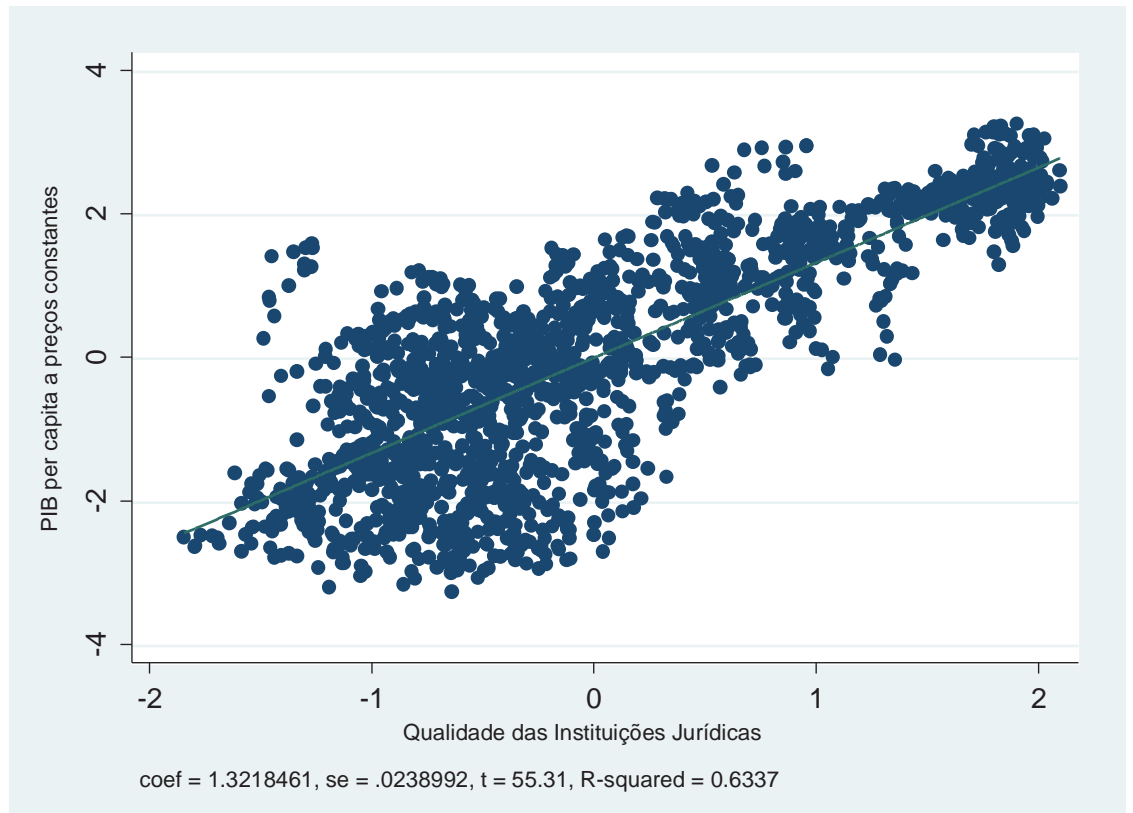

Fonte: Elaboração própria a partir de dados do Banco Mundial, com a utilização do software estatístico Stata.

Com vistas a analisar se as relaçóes dinâmicas entre as variáveis do modelo realmente diferem entre grupos de países, a amostra foi dividida em três grupos, conforme os níveis de renda: economias de alta, média e baixa renda, de acordo com a classificação estabelecida pelo Banco Mundial ${ }^{32}$.

As figuras referentes às respostas do PIB per capita a um choque na qualidade das instituições jurídicas estão compiladas na Figura 2.

Ao analisar os resultados relativos ao grupo de países de renda alta, observa-se que os efeitos de uma melhoria da qualidade institucional jurídica sobre o crescimento econô-

32 Ver World Bank Atlas Method (https://datahelpdesk.worldbank.org/knowledgebase/articles/378832what-is-the-world-bank-atlas-method), para maiores detalhes acerca da metodologia utilizada pelo Banco Mundial para classificação dos países conforme o nível de renda. 
mico são significativamente menores do que os efeitos médios encontrados na estimação da amostra de países de baixa renda. Assim, uma melhoria da qualidade das instituiçóes jurídicas em países de renda alta gera um aumento do PIB per capita desses países, com um pico equivalente a $0,93 \%$ logo no primeiro ano após o choque. Por outro lado, as respostas do PIB per capita ao choque nos países de renda baixa apresentam magnitudes maiores, com um pico de aumento de 1,52\%. Já os países de renda média, grupo maior e mais heterogêneo, apresentam um pico de aumento de $0,98 \%$ na trajetória de crescimento do PIB per capita. A Tabela 2 descreve os países que fazem parte de cada grupo.

Esses resultados estão de acordo com a hipótese de convergência de renda, que especifica uma relação negativa entre o nível de renda inicial dos países e a sua taxa de crescimento durante determinado período de tempo. Neste sentido, pode-se considerar que países que apresentam maior nível de renda, em geral, já possuem instituiçóes jurídicas mais fortes e, consequentemente, os efeitos de melhorias da qualidade dessas instituiçóes geram menor impacto sobre o crescimento econômico desses países se comparados com países de baixa renda. Sendo assim, os efeitos de um choque de melhoria da qualidade institucional jurídica tendem a ser mais relevantes e significativos em países de baixa renda que apresentam instituiçóes relativamente mais fracas.

Portanto, em países de baixa renda que, em geral, apresentam fraquezas e lacunas institucionais, os efeitos de melhorias do nível de qualidade das instituiçóes jurídicas parecem desempenhar um papel determinante para o crescimento econômico desses países. Por outro lado, países que apresentam maior nível de renda, possuem instituiçóes mais fortes, capazes de lidar de forma mais apropriada com períodos de desaceleraçóes e instabilidades econômicas, decorrentes de crises internas e externas. Já países que apresentam instituiçóes fracas são incapazes de lidar adequadamente com essas instabilidades. Logo, melhorias da qualidade das instituiçóes jurídicas em países de rendas mais baixas são necessárias e urgentes.

\section{Figura 2: Choques de Melhorias do Nível de Qualidade das Instituiçôes Jurídicas sobre o Crescimento Econômico - Grupos de Países por Nível de Renda}

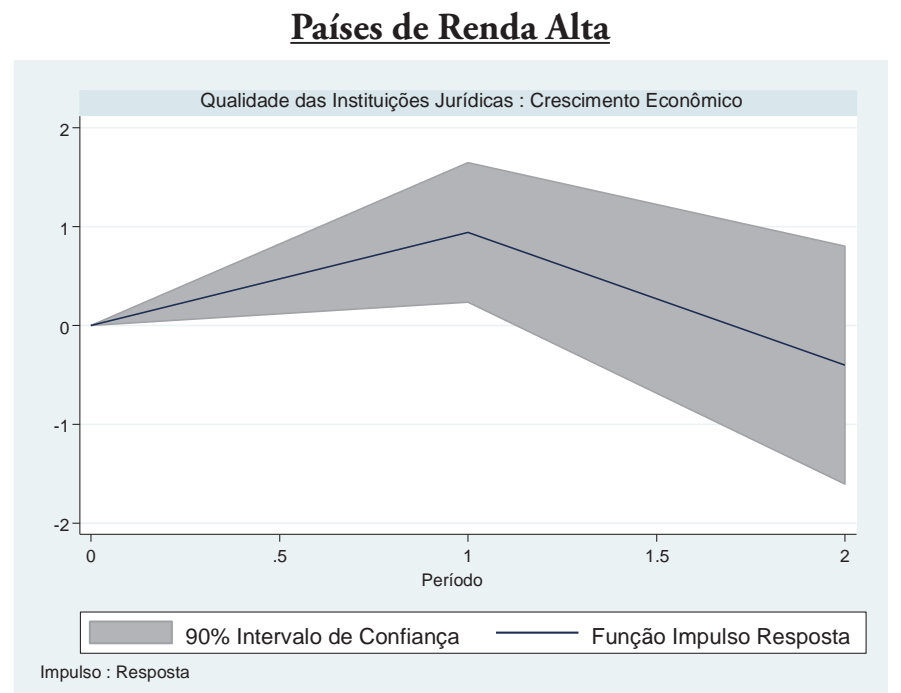


Países de Renda Média

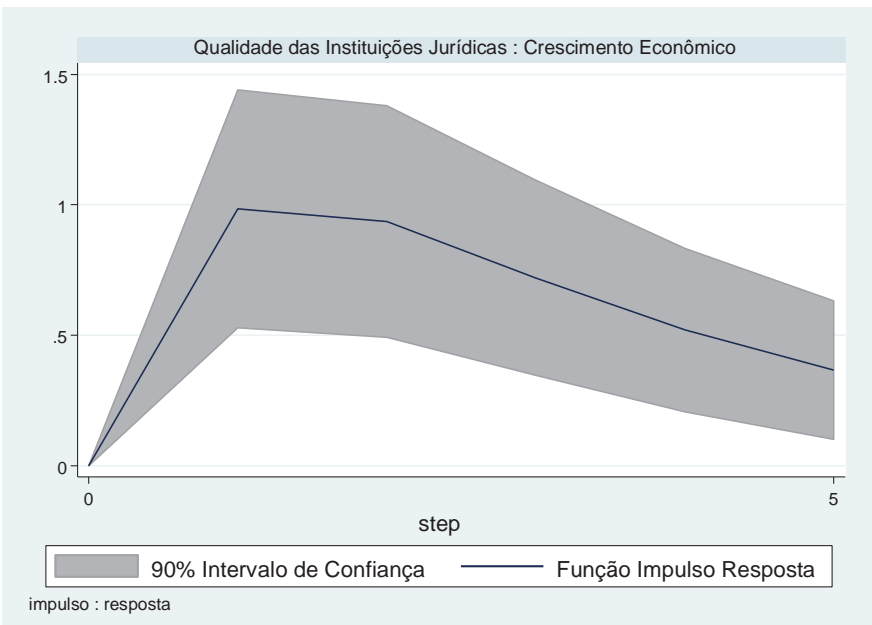

Países de Renda Baixa

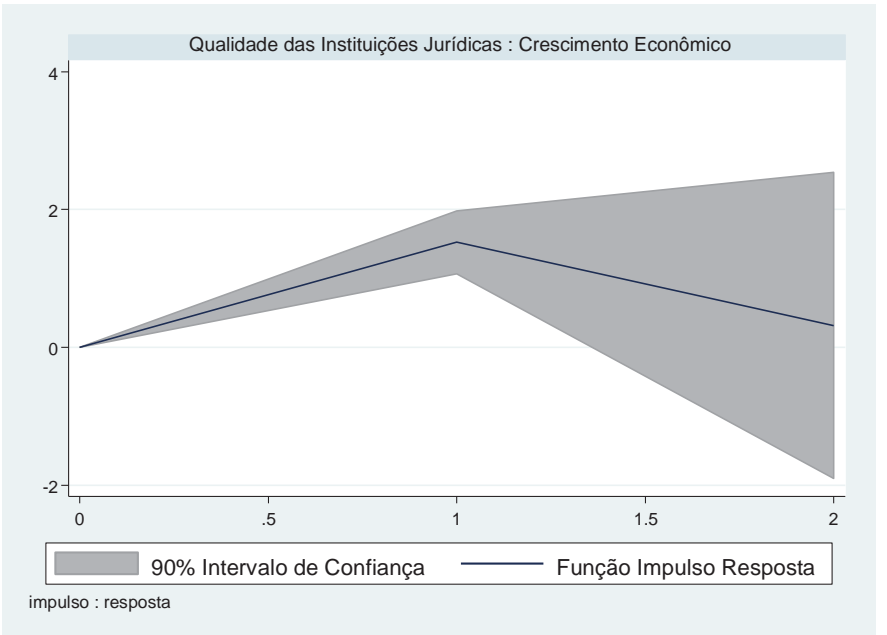

Fonte: Elaboração própria a partir de dados do Banco Mundial, com a utilização do software estatístico Stata. 
Tabela 2: Grupos de Países conforme o Nível de Renda

\begin{tabular}{cl}
\hline Nível de Renda & \multicolumn{1}{c}{ Países } \\
\hline & Austrália, Bahrein, Bélgica, Canadá, Chile, República Che- \\
ca, Dinamarca, Finlândia, França, Alemanha, Grécia, Hun- \\
gria, Irlanda, Israel, Itália, Japão, Coréia do Sul, Luxem- \\
burgo, Nova Zelândia, Noruega, Omã, Polônia, Portugal, \\
Catar, Arábia Saudita, Cingapura, Eslováquia, Eslovênia, \\
Espanha, Suécia, Suíça, Trindade e Tobago, Emirados Ára- \\
bes, Reino Unido, Estados Unidos e Uruguai. \\
Albânia, Algéria, Argentina, Armênia, Azerbaijão, Ban- \\
gladesh, Bielorrússia, Bolívia, Botsuana, Brasil, Bungária, \\
Camboja, Camarões, China, colômbia, Costa Rica, Croácia, \\
República Dominicana, Equador, Egito, El Salvador, Guiné \\
Equatorial, Georgia, Gana, Guatemala, Guiana, Honduras, \\
Índia, Indonésia, Irã, Jamaica, Jordânia, Casaquistão, Quê- \\
nia, Quirguistão, Líbano, Macedônia, Maurício, México, \\
Moldova, Mongólia, Marrocos, Namíbia, Nicarágua, Nigé- \\
ria, Paquistão, Panamá, Paraguai, Peru, Filipinas, Romênia, \\
Rússia, África do Sul, Sri Lanka, Suriname, Suazilândia, \\
Tajiquistão, Tailândia, Tunísia, Turquia, Ucrânia e Vietnã. \\
\hline Benin, Burquina Faso, República Centro-Africana, Chade, \\
Guiné, Guiné-Bissau, Haiti, Madagascar, Malawi, Malásia, \\
Mali, Moçambique, Nepal, Nigéria, Ruanda, Senegal, Serra \\
Leoa, Tanzânia, Togo e Uganda. \\
\hline
\end{tabular}

Fonte: Elaboração própria a partir de dados do Banco Mundial.

\section{CONSIDERAÇÓES FINAIS}

Este artigo buscou evidenciar a importância de se incorporar a análise institucional jurídica no estudo do desempenho econômico dos países. Com vistas a investigar a relação existente entre o nível de qualidade das instituições jurídicas vigentes nos países e os seus respectivos níveis de crescimento econômico, utilizou-se uma metodologia econométrica, referente à modelagem de vetores autorregressivos para dados em painel, e dados referentes a um conjunto de 118 países, que foram divididos em amostras de acordo com o nível de renda.

As estimaçóes foram realizadas com o intuito de demonstrar os efeitos de um choque positivo na variável representativa da qualidade das instituiçóes jurídicas sobre a trajetória futura do desempenho econômico dos países.

Os resultados das estimaçôes mostraram que, em média, um choque de melhoria da qualidade das instituiçóes jurídicas gera efeitos positivos sobre o PIB per capita no período imediatamente posterior ao choque. Ao analisar os resultados relativos ao grupo de países 
de renda alta, observou-se que os efeitos de uma melhoria da qualidade institucional jurídica sobre o crescimento econômico são significativamente menores do que os efeitos médios encontrados na estimação da amostra de países de baixa renda. Portanto, esses resultados estão de acordo com a hipótese de convergência de renda. Neste contexto, pode-se considerar que países que apresentam maior nível de renda, em geral, já possuem instituiçóes jurídicas mais fortes e, consequentemente, os efeitos de melhorias da qualidade dessas instituiçóes geram menor impacto sobre o crescimento econômico desses países se comparados com países de baixa renda. Sendo assim, os efeitos de um choque de melhoria da qualidade institucional jurídica tendem a ser mais relevantes e significativos em países de baixa renda que apresentam instituiçóes relativamente mais fracas.

Uma possível explicação para esses resultados é que, em países de baixa renda que, em geral, apresentam fraquezas e lacunas institucionais, os efeitos de melhorias do nível de qualidade das instituiçóes jurídicas parecem desempenhar um papel determinante para o crescimento econômico desses países. Por outro lado, países que apresentam maior nível de renda, possuem instituiçóes mais fortes, capazes de lidar de forma mais apropriada com períodos de desaceleraçóes e instabilidades econômicas, decorrentes de crises internas e externas. Já países que apresentam instituiçóes fracas são incapazes de lidar adequadamente com essas instabilidades. Logo, melhorias da qualidade das instituiçóes jurídicas em países de rendas mais baixas são necessárias e urgentes.

Em síntese, os resultados sugerem que melhorias na qualidade das instituiçóes jurídicas afetam positivamente o desempenho econômico, contribuindo para uma trajetória de crescimento econômico dos países. Compreender como a qualidade das instituiçôes jurídicas vigentes afeta o desempenho econômico de um país permite identificar a estrutura de incentivos e desincentivos que norteia o crescimento e desenvolvimento econômico dos países.

\section{REFERÊNCIAS}

ACEMOGLU, D., JOHNSON, S., ROBINSON, J.A. Institutional causes, macroeconomic symptoms: volatility, crises and growth. Journal of monetary economics, Amsterdam, NL, Vol. 50, No. 1, p. 49-123, 2003.

ANNAN, Kofi. The rule of law and transitional justice in conflict and post-conflict societies. Report of the Secretary-General, 2004.

AOKI, Masahiko. Towards a Comparative Institutional Analysis. MIT Press, 2001.

BOBBIO, Norberto. Teoria da norma jurídica. São Paulo: Edipro, 2001.

CHEMIN, M. The impact of the judiciary on entrepreneurship: Evaluation of Pakistan's "Access to Justice Programme". Journal of Public Economics, Amsterdam, NL, Vol. 93, No. 1/2, p.114$125,2009$.

DAM, Kenneth W. The judiciary and economic development. U Chicago Law \& Economics, Olin Working Paper, n. 287, 2006. 
GADELHA, A.; DIVINO, J. A. Institutions, growth and economic stability. Economics Bulletin, Vol. 39, n. 1, p. 554-563, 2019.

GÓES, Carlos. Institutions and growth: A GMM/IV panel VAR approach. Economics Letters, Amsterdam, NL, Vol. 138, p. 85-91, 2016.

IPPOLITI, R.; MELCARNE, A.; RAMELLO, G. B. Judicial eciency and entrepreneurs' expectations on the reliability of European legal systems. European Journal of Law and Economics, Vol. 40, No. 1, p.75-94, 2015.

JOHNSON, S., MCMILLAN, J., WOODRUFF, C. Courts and Relational Contracts. Journal of Law, Economics, and Organization, New Haven, Conn, Vol. 18, No. 1, p.221-277, 2002.

KAUFMANN, Daniel; KRAAY, Aart; MASTRUZZI, Massimo. The worldwide governance indicators: methodology and analytical issues. Hague Journal on the Rule of Law, Heidelberg, GE, Vol. 3, No. 2, p. 220-246, 2011.

KRYGIER, M. Rule of law. In: WRIGHT, JD (Ed.) Encyclopedia of the Social and Behavioral Sciences. 2.ed. Atlanta, GA: Elsevier, 2015. pp. 45-59.

LA PORTA, Rafael; LOPEZ-DE-SILANES, Florencio; SHLEIFER, Andrei. The economic consequences of legal origins. Journal of Economic Literature, Pittsburgh, PA, Vol. 46, No. 2, p. 285-332, 2008.

NORTH, Douglass Cecil. Structure and change in economic history. Norton, 1981.

NORTH, Douglass Cecil. Institutions. Journal of Economic Perspectives, Nashville, TN, Vol. 5, No. 1, p. 97-112, 1991.

ROLAND, Gerard. Understanding Institutional Change: Fast-moving and Slow-moving institutions. Studies in Comparative International Development, Saint Louis, MO, Vol. 38, No. 4, Winter 2004, p.109-131.

WATSON, P. The Rule of Law and Economic Prosperity, 2003. 